\title{
Clinical profiles and quality of care of subjects with type 2 diabetes according to their cardiovascular risk: an observational, retrospective study
}

\author{
Basilio Pintaudi ${ }^{1}$, Alessia Scatena ${ }^{2}$, Gabriella Piscitelli ${ }^{3}$, Vera Frison ${ }^{4}$, Salvatore Corrao ${ }^{5}$, Valeria Manicardi ${ }^{6}$, \\ Giusi Graziano ${ }^{7}$, Maria Chiara Rossi ${ }^{7}$, Marco Gallo $^{8}$, Domenico Mannino ${ }^{9}$, Paolo Di Bartolo ${ }^{10}$ \\ and Antonio Nicolucci ${ }^{7^{*}}$ (D)
}

\begin{abstract}
Background: The European Society of Cardiology (ESC) recently defined cardiovascular risk classes for subjects with diabetes. Aim of this study was to explore the distribution of subjects with type 2 diabetes (T2D) by cardiovascular risk groups according to the ESC classification and to describe the quality indicators of care, with particular regard to cardiovascular risk factors.

Methods: The study is based on data extracted from electronic medical records of patients treated at the 258 Italian diabetes centers participating in the AMD Annals initiative. Patients with T2D were stratified by cardiovascular risk. General descriptive indicators, measures of intermediate outcomes, intensity/appropriateness of pharmacological treatment for diabetes and cardiovascular risk factors, presence of other complications and overall quality of care were evaluated.

Results: Overall, 473,740 subjects with type 2 diabetes (78.5\% at very high cardiovascular risk, 20.9\% at high risk and $0.6 \%$ at moderate risk) were evaluated. Among people with T2D at very high risk: $26.4 \%$ had retinopathy, $39.5 \%$ had albuminuria, $18.7 \%$ had a previous major cardiovascular event, 39.0\% had organ damage, $89.1 \%$ had three or more risk factors. The use of DPP4-i markedly increased as cardiovascular risk increased. The prescription of secretagogues also increased and that of GLP1-RAs tended to increase. The use of SGLT2-i was still limited, and only slightly higher in subjects with very high cardiovascular risk. The overall quality of care, as summarized by the $\mathrm{Q}$ score, tended to be lower as the level of cardiovascular risk increased.
\end{abstract}

Conclusions: A large proportion of subjects with T2D is at high or very high risk. Glucose-lowering drug therapies seem not to be adequately used with respect to their potential advantages in terms of cardiovascular risk reduction. Several actions are necessary to improve the quality of care.

Keywords: Cardiovascular risk, Type 2 diabetes, Quality of care

*Correspondence: nicolucci@coresearch.it

${ }^{7}$ Center for Outcomes Research and Clinical Epidemiology, CORESEARCH, Corso Umberto I, 65122 Pescara, Italy

Full list of author information is available at the end of the article

\section{Background}

Type 2 diabetes (T2D) is associated with increased cardiovascular morbidity and mortality [1]. Patients with T2D have a significant increase in the risk of coronary heart disease and ischemic stroke and a 1.5 to 3.6 fold

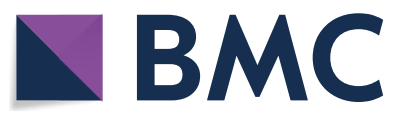

(c) The Author(s) 2021. This article is licensed under a Creative Commons Attribution 4.0 International License, which permits use, sharing, adaptation, distribution and reproduction in any medium or format, as long as you give appropriate credit to the original author(s) and the source, provide a link to the Creative Commons licence, and indicate if changes were made. The images or other third party material in this article are included in the article's Creative Commons licence, unless indicated otherwise in a credit line to the material. If material is not included in the article's Creative Commons licence and your intended use is not permitted by statutory regulation or exceeds the permitted use, you will need to obtain permission directly from the copyright holder. To view a copy of this licence, visit http://creativeco mmons.org/licenses/by/4.0/. The Creative Commons Public Domain Dedication waiver (http://creativecommons.org/publicdomain/ zero/1.0/) applies to the data made available in this article, unless otherwise stated in a credit line to the data. 
increase in mortality [1]. Diabetes is also an important risk factor for heart failure, peripheral artery disease, and microvascular complications, negatively impacting quality of life and life expectancy. It is estimated that patients with diabetes have a reduction in life expectancy of about 4-8 years, compared to individuals without diabetes [2,3]. Although great advances in prevention and therapy have resulted in significant reductions in diabetes-related cardiovascular mortality, cardiovascular risk still remains high in most patients with diabetes. Considering the growing number of survivors of cardiovascular events and the global diabetes epidemic, the number of T2D patients at higher cardiovascular risk is expected to increase, this posing a major challenge to healthcare systems. Therefore, the implementation of cost-effective strategies for cardiovascular risk reduction in this population is urgent [4]. Recent evidence indicates that the cardiovascular risk in T2D is highly heterogeneous, being it not universally similar to the risk of patients with previous cardiovascular disease [5-8].

The stratification of people with diabetes into different groups at different cardiovascular risk allows the recognition of those who could benefit most from more intensive cardiovascular prevention. Therefore, it may be useful to develop rational strategies to more intensively detect and treat patients at higher risk, while it may be reasonable and economically sound to use less intensive therapeutic approaches in those at lower cardiovascular risk.

Recently, the guidelines of the European Society of Cardiology (ESC) in collaboration with the European Society for the Study of Diabetes (EASD) [9] proposed a stratification of cardiovascular risk among people with diabetes based on the presence of established atherosclerotic disease, organ damage (proteinuria, eGFR $<30 \mathrm{ml} /$ $\mathrm{min} / 1.73 \mathrm{~m}^{2}$, left ventricular hypertrophy, retinopathy), or multiple risk factors (age, smoking, obesity, hypertension, dyslipidemia). This stratification subdivides people with diabetes into three groups: very high risk (10-year event risk $>10 \%$ ), high risk (between 5 and 10\%), and moderate risk $(<5 \%)$. The proposed stratification has important implications both on the therapeutic targets to be reached and the choice of treatment.

In light of this new classification, aim of this study was to explore the distribution and clinical characteristics of subjects with T2D cared for by Italian diabetes centers according to cardiovascular risk groups and to describe quality of care indicators, with particular reference to cardiovascular risk factors.

\section{Methods}

This was an observational, retrospective study including a large sample of patients cared for by 258 Italian diabetes clinics participating in the Annals initiative of the Italian Association of Clinical Diabetologists [Associazione Medici Diabetologi (AMD)] during 2018. AMD Annals is a monitoring and continuous quality of care improvement national initiative. This initiative is based on clinical data stored in electronic medical records of a large network of diabetes clinics, which are periodically extracted and used to assess specific quality indicators of diabetes care. All participating diabetes centers obtained the authorization of local Ethics Committees. A software was developed to enable the extraction of the information needed from electronic medical record systems used for the everyday management of outpatients [10]. Patients with type 2 diabetes were stratified on the base of their cardiovascular risk, according to the recent European Society of Cardiology (ESC) guidelines [9]. General descriptive indicators, intermediate outcome measures regarding intensity and appropriateness of diabetes pharmacological therapy, cardiovascular risk factors, chronic complications, and overall health care quality were evaluated. The denominator of each indicator was represented by patients with at least one detection of the parameters during the index year. When more than one measurement for the same patient in the index year was available, the more recent value was considered.

Overall quality of health care was evaluated by the Q-Score [11-13], calculated from process and intermediate outcome measures of HbA1c, blood pressure, LDL cholesterol and microalbuminuria (detection in the last 12 months, achievement of specific targets and adequate therapy prescription). For each patient a score between 0 and 40 was calculated as increasing index of good quality of care. The Q-Score showed to predict the incidence of major cardiovascular events in previous studies. In particular, the three-year risk of developing a cardiovascular event was $80 \%$ higher in subjects with a score $<15$ and more than $20 \%$ higher in subjects with a score between 20 and 25 , as compared to subjects with a score $>25$ [11, 12]. Furthermore, the Q-Score predicted the variability of key risk factors for complications in Type 2 Diabetes [13].

Socio-demographic and clinical characteristics as well as health care quality indicators were expressed as mean and standard deviation or percentage and compared between the different risk classes with ANOVA or chisquare, for continuous or categorical variables, respectively. The results were calculated on non-missing values, without any imputation technique. A p value $<0.05$ was considered as statistically significant. All analyses were conducted with SAS software (version 9.4).

\section{Results}

Overall, 473.740 patients with type 2 diabetes were evaluated. When subjects were stratified according to their cardiovascular risk, $78.5 \%$ of them were at very high risk, 
$20.9 \%$ at high risk and $0.6 \%$ at moderate risk. Patients characteristics by the different risk classes are reported in Table 1. The class of moderate risk was small. It included subjects with a low mean age and a short diabetes duration; a quarter of subjects were newly-diagnosed; BMI levels were significantly lower than the other risk classes. No gender difference between the cardiovascular risk classes was detected. Among high-risk subjects, $44.7 \%$ had at least a ten years diabetes duration. Among subjects at very high risk, $18.7 \%$ had a history of major cardiovascular event, $26.4 \%$ had retinopathy, $39.5 \%$ albuminuria and $8.8 \%$ eGFR $<30 \mathrm{ml} / \mathrm{min} / \mathrm{m}^{2}$, and $89.1 \%$ had three or more cardiovascular risk factors. With regard to anti-hyperglycemic drugs, the use of DPP4-inhibitors increased with increasing cardiovascular risk; for secretagogues the same trend was documented. A linear increase, even though within low percentages, was observed also for GLP1-RAs. The use of SGLT2 inhibitors was also limited and only slightly higher in very high risk subjects. As expected, the highest percentage of subjects treated with insulin was detected in the very high risk group.

Health care quality indicators are reported in Table 2. In the very high risk class, the percentage of patients with HbAlc $>8.0 \%$ was lower and the percentage of patients with $\mathrm{LDL}<100 \mathrm{mg} / \mathrm{dl}$ was higher than the other classes. Conversely, in this class the percentage of patients with high blood pressure values and the percentage of obese patients were higher compared with the other classes.

Indicators of therapeutic intensity reiterated greater attention to subjects at higher risk, except for the very high percentage of patients with inadequate blood pressure values despite antihypertensive therapy.

Q-score data documented lower mean scores in the highest cardiovascular risk classes. The percentage of subjects with a $\mathrm{Q}$-score $<15$ was very low in all groups.

\section{Discussion}

Diabetes has long been considered an equivalent of cardiovascular risk. This claim was based on the results of a Finnish study [14], in which patients with T2D without coronary artery disease (CHD) had a coronary artery mortality rate similar to that of subjects without diabetes who had had a previous coronary event. Diabetes also increases coronary death rates due to the worse prognosis after having the first event of coronary heart disease. These arguments have led in the past to recommend that diabetic patients should be treated as a separate high-risk category, without the need for stratification [15].

However, recent evidence indicates that the risk of CHD in T2D is not universally similar to the risk of patients with previous cardiovascular disease, but is highly heterogeneous. A meta-analysis of 13 epidemiological studies, including 45.108 patients with and without diabetes, found that in T2D patients without prior CHD the risk of $\mathrm{CHD}$ was $43 \%$ lower than individuals without diabetes with a prior myocardial infarction [5]. In a large population cohort [6] that included 1.586 .061 adults aged 30 to 90 years followed for 10 years, the risk of coronary artery disease was much lower among subjects with T2D without CHD than in patients with CHD without diabetes, compared to patients without neither CHD, nor T2D [HR: 1.70 (95\% CI 1.66-1.74) vs. 2.80 (95\% CI 2.70-2.85), respectively]. In another meta-analysis of observational studies in patients with DM2 [7], cardiovascular risk was assessed by the coronary calcium score at baseline. The Authors found a prevalence of $28.5 \%$ of patients with a calcium score of zero, indicating a 5-year survival rate similar to that of patients without diabetes [8]. Therefore, a subgroup with lower CHD risk is likely to exist, particularly including patients younger than 40 years with a short disease duration.

In line with these findings, we found that a large proportion of patients show a 10-year risk of major cardiovascular events over $10 \%$, due to the presence of a previous cardiovascular event, organ damage, or multiple cardiovascular risk factors. However, a small percentage of the study population could be considered ad intermediate risk (i.e. below 5\%), thus confirming the existence of a continuum in cardiovascular risk among people with T2D. Furthermore, our study population was represented by patients attending diabetes clinics; as such, the proportion of individuals with moderate risk was presumably underestimated. Also, in our study population the prevalence of established cardiovascular disease was $18.7 \%$, lower than the $30 \%$ European prevalence among patients with T2D reported by Einarson et al. [16]. However, in the same paper, the prevalence of CVD disease in Italy was reported to be $14.8 \%$.

Once it is clear that the cardiovascular risk profile is heterogeneous, it is necessary to focus on the most advantageous and appropriate therapeutic strategy for each risk class. Our data showed that, after metformin and insulin, the use of DPP4-i drugs is prevalent. This pharmacological class has shown neutral effects from the cardiovascular point of view for almost all the molecules of the class [17]. Their use in the highest risk class does not appear completely justified when compared with the underutilization of some pharmacological classes with proven cardiovascular benefit (i.e. GLP1-RA and SGLT2i) $[18-21]$.

The mechanisms underlying the drug-related reduction of cardiovascular outcomes associated with the use of SGLT2-i and GLP1-RA are still under investigation [22]; however, their clinical utility goes uncontested [23]. In addition to the direct effect of these drugs on the 
Table 1 Characteristics of type 2 diabetes population according to cardiovascular risk

\begin{tabular}{|c|c|c|c|c|}
\hline & Moderate risk & High risk & Very high risk & $p$ \\
\hline Number of subjects & 2,819 & 98,781 & 372,140 & \\
\hline Age (years) & $41.6 \pm 6.8$ & $66.7 \pm 13.1$ & $70.0 \pm 10.2$ & $<0.0001$ \\
\hline Sex (\% male) & 57.6 & 56.5 & 57.2 & 0.0003 \\
\hline New diagnoses (\%) & 25.3 & 9.9 & 4.9 & $<0.0001$ \\
\hline Diabetes duration (years) & $3.0 \pm 2.8$ & $10.1 \pm 8.9$ & $12.9 \pm 9.5$ & $<0.0001$ \\
\hline $\mathrm{BMI}\left(\mathrm{kg} / \mathrm{m}^{2}\right)$ & $25.6 \pm 2.8$ & $27.0 \pm 4.5$ & $30.0 \pm 5.5$ & $<0.0001$ \\
\hline Smokers (\%) & 0.0 & 7.6 & 19.2 & $<0.0001$ \\
\hline HbA1c (\%) & $7.3 \pm 1.7$ & $7.1 \pm 1.3$ & $7.2 \pm 1.2$ & 0.002 \\
\hline \multicolumn{5}{|l|}{ Blood pressure (mmHg) } \\
\hline Systolic & $116.4 \pm 11.2$ & $130.1 \pm 17.0$ & $136.5 \pm 18.3$ & $<0.0001$ \\
\hline Dyastolic & $73.3 \pm 7.7$ & $75.9 \pm 9.2$ & $76.9 \pm 9.7$ & $<0.0001$ \\
\hline Total Cholesterol (mg/dl) & $175.1 \pm 31.2$ & $174.0 \pm 33.9$ & $167.1 \pm 38.8$ & $<0.0001$ \\
\hline LDL Cholesterol (mg/dl) & $97.8 \pm 20.6$ & $97.2 \pm 27.8$ & $91.0 \pm 32.7$ & $<0.0001$ \\
\hline HDL Cholesterol(mg/dl) & $48.5 \pm 13.2$ & $51.1 \pm 13.7$ & $48.1 \pm 12.7$ & $<0.0001$ \\
\hline Triglicerides (mg/dl) & $135.8 \pm 106.0$ & $125.8 \pm 78.1$ & $141.1 \pm 81.6$ & $<0.0001$ \\
\hline Albuminuria (\%) & 0.0 & 0.0 & 39.5 & $<0.0001$ \\
\hline $\mathrm{eGFR}<30 \mathrm{ml} / \mathrm{min} / 1,73 \mathrm{~m}^{2}(\%)$ & 0.0 & 0.0 & 8.8 & $<0.0001$ \\
\hline \multicolumn{5}{|l|}{ Anti-hyperglycemic therapy (\%) } \\
\hline Metformin & 72.0 & 71.1 & 69.0 & $<0.0001$ \\
\hline DPP4-i & 13.3 & 19.8 & 21.5 & $<0.0001$ \\
\hline Secretagogues & 7.7 & 15.9 & 16.3 & $<0.0001$ \\
\hline Glinides & 1.2 & 3.6 & 3.7 & $<0.0001$ \\
\hline SGLT2-i & 8.5 & 7.7 & 10.0 & $<0.0001$ \\
\hline Glitazones & 3.1 & 4.0 & 4.4 & $<0.0001$ \\
\hline Acarbose & 1.1 & 2.0 & 2.5 & $<0.0001$ \\
\hline GLP1-RA & 2.4 & 3.9 & 6.4 & $<0.0001$ \\
\hline Insulin & 27.6 & 24.4 & 34.5 & $<0.0001$ \\
\hline \multicolumn{5}{|l|}{ Diabetes treatment scheme (\%) } \\
\hline Oral Monotherapy & 38.1 & 35.7 & 27.4 & $<0.0001$ \\
\hline Oral Two fold therapy & 19.2 & 23.0 & 21.7 & $<0.0001$ \\
\hline Three or more oral drugs & 3.3 & 6.0 & 6.5 & $<0.0001$ \\
\hline GLP1-RA \pm other drugs & 2.4 & 3.9 & 6.4 & $<0.0001$ \\
\hline Insulin + oral drugs & 12.8 & 12.8 & 19.1 & $<0.0001$ \\
\hline Multiple daily insulin injections & 14.5 & 10.9 & 14.2 & $<0.0001$ \\
\hline Anti-hypertensive therapy (\%) & 0.0 & 32.9 & 80.4 & $<0.0001$ \\
\hline Lipid-lowering therapy (\%) & 0.0 & 18.0 & 72.6 & $<0.0001$ \\
\hline Retinopathy (\%) & 0.0 & 0.0 & 26.4 & $<0.0001$ \\
\hline Non proliferative & 0.0 & 0.0 & 19.5 & \\
\hline Pre-proliferative & 0.0 & 0.0 & 1.9 & \\
\hline Proliferative & 0.0 & 0.0 & 1.8 & \\
\hline Laser-treated & 0.0 & 0.0 & 2.6 & \\
\hline Oftalmopathy & 0.0 & 0.0 & 0.2 & \\
\hline Blindness & 0.0 & 0.0 & 0.3 & \\
\hline Previous myocardial infarction (\%) & 0.0 & 0.0 & 9.5 & $<0.0001$ \\
\hline Previous stroke (\%) & 0.0 & 0.0 & 3.3 & $<0.0001$ \\
\hline Established cardiovascular disease (\%) & 0.0 & 0.0 & 18.7 & $<0.0001$ \\
\hline Dialisys (\%) & 0.0 & 0.0 & 0.3 & $<0.0001$ \\
\hline
\end{tabular}


Table 2 Health care quality indicators according to cardiovascular risk

\begin{tabular}{|c|c|c|c|c|}
\hline & Moderate risk & High risk & Very high risk & $\mathrm{p}$ \\
\hline $\mathrm{HbA1c} \leq 7.0 \%(\%)$ & 57.4 & 58.0 & 51.6 & $<0.0001$ \\
\hline $\mathrm{HbA1c}>8.0 \%(\%)$ & 22.3 & 16.1 & 18.4 & $<0.0001$ \\
\hline Blood pressure $\geq 140 / 90 \mathrm{mmHg}(\%)$ & 0.0 & 31.0 & 50.8 & $<0.0001$ \\
\hline LDL Cholesterol < 100 mg/dl (\%) & 49.8 & 54.7 & 65.6 & $<0.0001$ \\
\hline LDL Cholesterol $\geq 130 \mathrm{mg} / \mathrm{dl}(\%)$ & 0.0 & 9.1 & 13.1 & $<0.0001$ \\
\hline Subjects with $\mathrm{HbA} 1 \mathrm{c} \leq 7.0 \%$, with C-LDL $<100 \mathrm{mg} / \mathrm{dl}$ and with $\mathrm{BP}<140 / 90 \mathrm{mmHg}(\%)$ & 31.0 & 24.3 & 18.6 & $<0.0001$ \\
\hline $\mathrm{BMI} \geq 30 \mathrm{~kg} / \mathrm{m}^{2}(\%)$ & 0.0 & 14.7 & 46.6 & $<0.0001$ \\
\hline Subjects not treated with insulin despite $\mathrm{HbA} 1 \mathrm{c} \geq 9.0 \%(\%)^{\mathrm{a}}$ & 39.2 & 38.4 & 25.5 & $<0.0001$ \\
\hline Subjects with $\mathrm{HbA} 1 \mathrm{c} \geq 9.0 \%$ despite insulin therapy $(\%)^{b}$ & 31.6 & 18.2 & 15.7 & $<0.0001$ \\
\hline Subjects not treated with anti-hypertensive despite $B P \geq 140 / 90 \mathrm{mmHg}(\%)^{c}$ & n.a & 48.2 & 22.5 & $<0.0001$ \\
\hline Subjects with $B P \geq 140 / 90 \mathrm{mmHg}$ despite anti-hypertensive therapy (\%) ${ }^{d}$ & n.a & 46.8 & 48.8 & $<0.0001$ \\
\hline Subjects not treated with lipid-lowering drugs despite C-LDL $\geq 130 \mathrm{mg} / \mathrm{dl}(\%)^{\mathrm{e}}$ & n.a & 60.1 & 45.5 & $<0.0001$ \\
\hline Subjects with C-LDL $\geq 130 \mathrm{mg} / \mathrm{dl}$ despite lipid-lowering therapy $(\%)^{f}$ & n.a & 16.9 & 9.7 & $<0.0001$ \\
\hline $\begin{array}{l}\text { Subjects with a previous } \mathrm{CV} \text { event (heart attack and/or stroke) treated with antiplatelet } \\
\text { therapy (\%) }\end{array}$ & n.a & n.a & 76.1 & - \\
\hline Mean Q Score & $32.2 \pm 6.8$ & $30.1 \pm 7.6$ & $28.2 \pm 8.3$ & $<0.0001$ \\
\hline Subjects with Q Score < 15 (\%) & 0.0 & 1.6 & 4.1 & $<0.0001$ \\
\hline Subjects with Q Score > 25 (\%) & 74.0 & 66.1 & 59.4 & $<0.0001$ \\
\hline
\end{tabular}

a Denominator: all the subjects with $\mathrm{HbA} 1 \mathrm{c} \geq 9.0 \%$

b Denominator: all the subjects treated with insulin

c Denominator: all the subjects with $\mathrm{BP} \geq 140 / 90 \mathrm{mmHg}$

d Denominator: all the patients treated with anti-hypertensive drugs

e Denominator: all the subjects with C-LDL $\geq 130 \mathrm{mg} / \mathrm{dl}$

$f$ Denominator: all the subjects treated with lipid-lowering drugs

n.a. notapplicable

cardiovascular system, optimal glycemic control remains essential [24].

The wide use of metformin in our study population is also justified by existing evidence. In particular, metformin use following acute myocardial infarction was associated with a reduction in risk of all-cause mortality [25]. On the other hand, a significant use of secretagogues and glinides in the classes with higher cardiovascular risk was documented. The use of these drugs raises concerns in particular due to the risk of hypoglycemic episodes and it has recently been associated with an increase in all-cause mortality [26].

To our knowledge, this is the first study investigating the clinical aspects and quality of care indicators in subjects with T2D according to the stratification of cardiovascular risk proposed by ESC. We have described detailed clinical characteristics of people attending Italian diabetes centers, thus allowing the identification of patients needing a more intensive care. The other novelty of our study consists in the assessment of health care quality indicators according to cardiovascular risk. This represents a relevant aspect to improve the level of care, overcome clinical inertia, and implement costeffective strategies for cardiovascular risk reduction. The implications of the findings of our study in the context of existing research are important. The large sample of patients studied allowed to consistently define the clinical characteristics of patients with diabetes belonging to the different cardiovascular risk classes. This could generate further studies useful for intercepting risk trajectories, in particular by studying the predictive factors for the transition of lower-risk subjects towards higher risk profiles. In this way, it will be possible to act preventively on the categories of the most vulnerable subjects and those with a higher likelihood of worsening their cardiovascular risk.

Our findings also underline the importance of a deeper involvement of cardiologists in the management of T2D and established cardiovascular disease, to ensure that cardio-protective therapies are used along with other evidence-based therapies to improve patient outcomes [27, 28].

Our study has limitations. First, data analyzed refer to 2018; however, it is unlikely that the characteristics of patients attending diabetes clinics have changed in the last two years. On the other hand, rates of use of the different antihyperglycemic classes may have changed in most recent years, in the light of the accumulation of a large body of evidence supporting the positive 
cardio-renal effects of SGLT2i and GLP1-RA. Finally, data on hospitalizations and hypoglycemic episodes were not available; however, the history of major cardiovascular events was derived directly from electronic medical records.

\section{Conclusions}

Our study showed that the majority of individuals with T2D has a very high cardiovascular risk. We were able to define the features of the subjects at moderate risk. It included subjects with a very low mean age, a short diabetes duration and a low BMI. The analysis of pharmacological therapies showed an unexpected underuse of the classes of anti-hyperglycemic drugs that can offer cardiovascular protection, particularly GLP1-RA and SGLT2-i.

The assessment of the level of quality of care showed different areas of intervention on which to target therapeutic and preventive action. Intervention on modifiable risk factors such as BMI and smoking should be carefully considered during clinical practice. The finding of a large percentage of subjects with high blood pressure values in the very high risk class requires a reflection on the role of the diabetes specialist in the management of cardiovascular risk factors. Risk stratification can help healthcare professionals to better personalize the care of different types of patients. Specifically, the use of antihyperglycemic drugs with documented positive cardiovascular effects is desirable. The stratification could also raise awareness among stakeholders on the identification of more efficient cardiovascular diagnostic-therapeutic pathways. Further studies are needed to test the effect of differentiated care processes on different risk categories from both a clinical and an economic point of view.

\begin{abstract}
Abbreviations
T2D: Type 2 Diabetes; DPP4-i: Dipeptidil Peptidasi 4- inhibitor; GLP1-RA: Glucagon-Like Peptide 1-Receptor Agonist; SGLT2-i: Sodium-GLucose coTransporter-2 inhibitors; BMl: Body Mass Index.
\end{abstract}

\section{Acknowledgements}

The Authors would like to thank all the AMD Annals initiative investigators.

\section{Authors' contributions}

$A N, B P$, contributed to the study design and the interpretation of data. BP, $M C R, G G$ and $A N$ had the main responsibility for analyzing data and writing the first draft of the paper. BP, AS, GP, VF, SC, VM, GG, MCR, MG, DM, PDB and AN critically revised the manuscript. $A N$ is the guarantor of this work and, as such, had full access to all the data in the study and takes responsibility for the integrity of the data and the accuracy of the data analysis. All authors read and approved the final manuscript.

\section{Funding}

The study was supported by an unrestricted grant by AstraZeneca, Italy. The sponsor had no role in the study design, data collection, analysis, interpretation and in writing the paper.

\section{Availability of data and materials}

The datasets used and/or analyzed during the current study are available from the corresponding author on reasonable request.

\section{Ethics approval and consent to participate}

All participating diabetes centers obtained the authorization of local Ethics Committee.

\section{Consent for publication \\ Not applicable}

\section{Competing interests}

AN has received honoraria from AstraZeneca, Eli Lilly, Novo Nordisk, and research support from Alfasigma, Novo Nordisk, Sanofi, Shionogi, SOBI. MCR research support from Alfasigma, Novo Nordisk, Sanofi, Shionogi, SOBI. All the others authors do not declare any competing interest.

\section{Author details}

${ }^{1}$ Diabetes Unit, Niguarda Cà Granda Hospital, Milan, Italy. ${ }^{2}$ San Donato Hospital, Arezzo, Italy. ${ }^{3}$ Diabetology, ASST Nord Milan, Sesto San Giovanni, Italy. ${ }^{4}$ Internal Medicine and Diabetology Service, ULSS6 Cittadella, Italy. ${ }^{5}$ Department of Internal Medicine, ARNAS Civico Benfratelli Hospital, University of Palermo, Palermo, Italy. ${ }^{6}$ Diabetes Clinic, Azienda USL-IRCCS Di Reggio Emilia, Reggio Emilia, Italy. ${ }^{7}$ Center for Outcomes Research and Clinical Epidemiology, CORESEARCH, Corso Umberto I, 65122 Pescara, Italy. ${ }^{8}$ AOU Città Della Salute E Della Scienza, Presidio Ospedaliero Molinette, Torino, Italy.

${ }^{9}$ Endocrinology and Metabolic Unit, GOM, Reggio Calabria, Italy. ${ }^{10}$ AUSL

Diabetes Unit Romagna, Ravenna, Italy.

Received: 23 December 2020 Accepted: 22 February 2021

Published online: 06 March 2021

\section{References}

1. Sarwar N, Gao P, Seshasai SR, Gobin R, Kaptoge S, et al. Diabetes mellitus, fasting blood glucose concentration, and risk of vascular disease: a collaborative meta-analysis of 102 prospective studies. Lancet. 2010;375:2215-22.

2. Gu K, Cowie CC, Harris M. Mortality in adults with and without diabetes in a national cohort of the U.S. population. Diabetes Care. 1998;21:1138-45.

3. Rawshani A, Sattar N, Franzén S, et al. Excess mortality and cardiovascular disease in young adults with type 1 diabetes in relation to age at onset: a nationwide, register-based cohort study. Lancet. 2018;392:477-86.

4. Gregg EW, Zhuo X, Cheng YJ, Albright AL, Narayan KM, Thompson TJ. Trends in lifetime risk and years of life lost due to diabetes in the USA, 1985-2011: a modelling study. Lancet Diabetes Endocrinol. 2014;2:867-74.

5. Bulugahapitiya U, Siyambalapitiya S, Sithole J, Idris I. Is diabetes a coronary risk equivalent? Systematic review and meta-analysis. Diabet Med. 2009;26:142-8.

6. Rana JS, Liu JY, Moffet HH, Jaffe M, Karter AJ. Diabetes and prior coronary heart disease are not necessarily risk equivalent for future coronary heart disease events. J Gen Internal Med. 2016;31:387-93.

7. Kramer CK, Zinman B, Gross JL, Canani LH, Rodrigues TC, Azevedo MJ, Retnakaran R. Coronary artery calcium score prediction of all cause mortality and cardiovascular events in people with type 2 diabetes: systematic review and meta-analysis. BMJ. 2013;346:f1654.

8. Raggi P, Shaw LJ, Berman DS, Callister TQ. Prognostic value of coronary artery calcium screening in subjects with and without diabetes. J Am Coll Cardiol. 2004:43:1663-9.

9. Cosentino F, Grant PJ, Aboyans V, Bailey CJ, Ceriello A, Delgado V, Federici M, Filippatos G, Grobbee DE, Hansen TB, Huikuri HV, Johansson I, Jüni P, Lettino M, Marx N, Mellbin LG, Östgren CJ, Rocca B, Roffi M, Sattar N, Seferović PM, Sousa-Uva M, Valensi P, Wheeler DC, ESC Scientific Document Group. 2019ESC Guidelines on diabetes, pre-diabetes, and cardiovascular diseases developed in collaboration with the EASD. Eur Heart J. 2020;41:255-323.

10. Rossi MC, Nicolucci A, Arcangeli A, Cimino A, De Bigontina G, Giorda C, Meloncelli I, Pellegrini F, Valentini U, Vespasiani G, Associazione Medici Diabetologi AnnalsStudy Group. Baseline quality-of-care data from a 
quality-improvement program implemented by a network of diabetes outpatient clinics. Diabetes Care. 2008;31:2166-8.

11. De Berardis G, Pellegrini F, Franciosi M, Belfiglio M, Di Nardo B, Greenfield S, Kaplan SH, Rossi MC, Sacco M, Tognoni G, Valentini M, Nicolucci A, QuED (Quality of Care and Outcomes in Type 2 Diabetes) Study Group. Quality of diabetes care predicts the development of cardiovascular events: results of the QuED study. Nutr Metab Cardiovasc Dis. 2008;18:57-65.

12. Rossi MC, Lucisano G, Comaschi M, Coscelli C, Cucinotta D, Di Blasi $P_{\text {, }}$ Bader G, Pellegrini F, Valentini U, Vespasiani G, Nicolucci A, AMD-QUASAR Study Group. Quality of diabetes care predicts the development of cardiovascular events: results of the AMD-QUASAR study. Diabetes Care. 2011:34:347-52.

13. Ceriello A, Rossi MC, De Cosmo S, Lucisano G, Pontremoli R, Fioretto $P$, Giorda C, Pacilli A, Viazzi F, Russo G, Nicolucci A, AMD-Annals Study Group. Overall quality of care predicts the variability of key risk factors for complications in type 2 diabetes: an observational longitudinal retrospective study. Diabetes Care. 2019:42:514-9.

14. Haffner SM, Lehto S, Ronnemaa T, Pyorala K, Laakso M. Mortality from coronary heart disease in subjects with type 2 diabetes and in nondiabetic subjects with and without prior myocardial infarction. N Engl J Med. 1998;339:229-34.

15. Expert Panel on Detection E, Treatment of High Blood Cholesterol in A, Executive summary of the third report of The National Cholesterol Education Program (NCEP) expert panel on detection, evaluation, and treatment of high blood cholesterol in adults (adult treatment panel III). JAMA. 2001:285:2486-97.

16. Einarson TR, Acs A, Ludwig C, Panton UH. Prevalence of cardiovascular disease in type 2 diabetes: a systematic literature review of scientific evidence from across the world in 2007-2017. Cardiovasc Diabetol. 2018:17:83.

17. Zheng SL, Roddick AJ, Aghar-Jaffar R, Shun-Shin MJ, Francis D, Oliver N, Meeran K. Association between use of sodium-glucose cotransporter 2 inhibitors, glucagon-like peptide 1 agonists, and dipeptidyl peptidase 4 inhibitors with all-cause mortality in patients with type 2 diabetes: a systematic review and meta-analysis. JAMA. 2018;319:1580-91.

18. McGuire DK, Shih WJ, Cosentino F, Charbonnel B, Cherney DZI, DagogoJack S, Pratley R, Greenberg M, Wang S, Huyck S, Gantz I, Terra SG, Masiukiewicz U, Cannon CP. Association of SGLT2 inhibitors with cardiovascular and kidney outcomes in patients with type 2 diabetes: a meta-analysis. JAMA Cardiol. 2020;7:e204511.

19. Ghosh-Swaby OR, Goodman SG, Leiter LA, Cheng A, Connelly KA, Fitchett D, Jüni P, Farkouh ME, Udell JA. Glucose-lowering drugs or strategies, atherosclerotic cardiovascular events, and heart failure in people with or at risk of type 2 diabetes: an updated systematic review and meta-analysis of randomized cardiovascular outcome trials. Lancet Diabetes Endocrinol. 2020;8:418-35.

20. Kluger AY, Tecson KM, Lee AY, Lerma EV, Rangaswami J, Lepor NE, Cobble ME, McCullough PA. Class effects of SGLT2 inhibitors on cardiorenal outcomes. Cardiovasc Diabetol. 2019;18:99.
21. Bonora BM, Avogaro A, Fadini GP. Effects of exenatide long-acting release on cardiovascular events and mortality in patients with type 2 diabetes: a systematic review and meta-analysis of randomized controlled trials. Acta Diabetol. 2019;56:1051-60.

22. Lee MMY, Petrie MC, McMurray JJV, Sattar N. How do SGLT2 (sodiumglucose cotransporter 2) inhibitors and glp-1 (glucagon-like peptide-1) receptor agonists reduce cardiovascular outcomes? Completed and ongoing mechanistic trials. Arterioscler Thromb Vasc Biol. 2020;40:506-22.

23. Palmer SC, Tendal B, Mustafa RA, Vandvik PO, Li S, Hao Q, Tunnicliffe $D$, Ruospo M, Natale P, Saglimbene V, Nicolucci A, Johnson DW, Tonelli M, Rossi MC, Badve SV, Cho Y, Nadeau-Fredette AC, Burke M, Faruque LI, Lloyd A, Ahmad N, Liu Y, Tiv S, Millard T, Gagliardi L, Kolanu N, Barmanray RD, McMorrow R, Raygoza Cortez AK, White H, Chen X, Zhou X, Liu J, Rodríguez AF, González-Colmenero AD, Wang Y, Li L, Sutanto S, Solis RC, Díaz González-Colmenero F, Rodriguez-Gutierrez R, Walsh M, Guyatt G, Strippoli GFM. Sodium-glucose cotransporter protein-2 (SGLT-2) inhibitors and glucagon-like peptide-1 (GLP-1) receptor agonists for type 2 diabetes: systematic review and network meta-analysis of randomised controlled trials. BMJ. 2021;13(372):m4573.

24. Giugliano D, Chiodini P, Maiorino MI, Bellastella G, Esposito K. Cardiovascular outcome trials and major cardiovascular events: does glucose matter? A systematic review with meta-analysis. J Endocrinol Invest. 2019;42:1165-9.

25. Bromage DI, Godec TR, Pujades-Rodriguez M, Gonzalez-Izquierdo A, Denaxas $\mathrm{S}$, Hemingway $\mathrm{H}$, Yellon DM. Metformin use and cardiovascular outcomes after acute myocardial infarction in patients with type 2 diabetes: a cohort study. Cardiovasc Diabetol. 2019;18:168.

26. Mannucci E, Monami M, Candido R, Pintaudi B, Targher G, SID-AMD joint panel for Italian Guidelines on Treatment of Type 2 Diabetes. Effect of insulin secretagogues on major cardiovascular events and all-cause mortality: A meta-analysis of randomized controlled trials. Nutr Metab Cardiovasc Dis. 2020;30:1601-8.

27. O'Keefe JH, Nassif ME, Magwire ML, O'Keefe EL, Lavie CJ. The elephant in the room: why cardiologists should stop ignoring type 2 diabetes. Prog Cardiovasc Dis. 2019:62:364-9.

28. Ray KK, Del Prato S, Müller-Wieland D, Cariou B, Colhoun HM, Tinahones FJ, Domenger C, Letierce A, Mandel J, Samuel R, Bujas-Bobanovic M, Leiter LA. Alirocumab therapy in individuals with type 2 diabetes mellitus and atherosclerotic cardiovascular disease: analysis of the ODYSSEY DM-DYSLIPIDEMIA and DM-INSULIN studies. Cardiovasc Diabetol. 2019;18:149.

\section{Publisher's Note}

Springer Nature remains neutral with regard to jurisdictional claims in published maps and institutional affiliations.

Ready to submit your research? Choose BMC and benefit from:

- fast, convenient online submission

- thorough peer review by experienced researchers in your field

- rapid publication on acceptance

- support for research data, including large and complex data types

- gold Open Access which fosters wider collaboration and increased citations

- maximum visibility for your research: over $100 \mathrm{M}$ website views per year

At BMC, research is always in progress.

Learn more biomedcentral.com/submissions 